\title{
SILICON CARBIDE AND MAGNETORRESISTIVE TECHNOLOGIES FOR SOLID STATE POWER CONTROLLERS
}

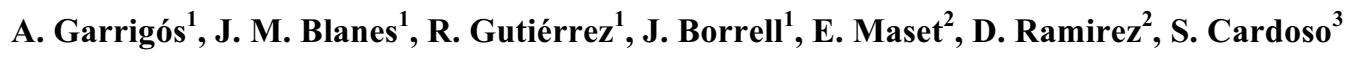 \\ ${ }^{1}$ Industrial Electronics Group, UMH, Spain, e-mail: augarsir@umh.es \\ ${ }^{2}$ Instrumentation and Industrial Electronics Laboratory, UV, Spain \\ ${ }^{3}$ INESC Microsystems and Nanotechnologies and Physics Dept, Instituto Superior Tecnico, UL, Portugal
}

\begin{abstract}
The aim of this paper is to make an introduction, review and preliminary investigation tasks of the application of Silicon Carbide (SiC) power semiconductors and magnetoresistive (MR) current sensors for Solid State Power Controllers (SSPCs) and controlled switches, especially for high temperature environment and/or high voltage applications.
\end{abstract}

\section{INTRODUCTION}

Wide BandGap (WBG) power semiconductors are nowadays being developed for many power conversion applications. In particular, Silicon Carbide ( $\mathrm{SiC}$ ) very attractive for high-voltage, high-power and high temperature conditions where traditional silicon semiconductors find serious limitations. During the last European Space Power Conference (ESPC 2014), a complete session was dedicated to WBG devices and applications, including a comprehensive paper of potential applications for the space sector [1]. In section 4.2 of that work appears an interesting application which actually is the staring point of this research "3. high voltage transistors can also be used as output power switches in ion-propulsion to improve the redundancy scheme and allow to connect the nominal or redundant converter to the nominal or redundant thruster".

The most relevant properties and prized properties of $\mathrm{SiC}$ are high critical electrical field, eight times higher than $\mathrm{Si}$, good thermal conductivity, three time higher and higher electron saturation velocity, two times higher Those characteristics impact directly on higher voltage, higher temperature and higher frequency of operation.

Second technology of interest is magnetoresistive (MR) current sensors. Shunt current sensing is probably the most used technique nowadays. Despite its simplicity and well-established technique for space applications they have some drawbacks which some of them could be exacerbated in high voltage applications. First, and the most obvious, it is an invasive method that consumes power and requires certain level of redundancy to avoid open-circuit failure of sensing resistor, but also, in high voltage applications, requires high voltage transistors (current mirror and output current source) to stand with operating voltages and achieve high CMRR. Galvanic isolation is also an interesting topic of discussion.

MR current sensing is becoming a promising alternative to shunt current sensing since overcomes some of the problems abovementioned. In addition, MR technology is widely spread in several space sensor applications (position, magnetometers...) and current sensing has also been investigated recently [2].

\section{SiC BASED SOLID STATE PROTECTION CIRCUITS: LITERATURE REVIEW}

Focusing on Solid State Power Controller (SSPC) and Solid State Circuit Breaker (SSCB), first found references that uses commercial devices date back to 2007 and 2008, when is suggested to conceive an SSPC using SiC JFET, $[3,4]$. The target was $270 \mathrm{Vdc}$ aircraft power distribution and the rationale behind was SiMOSFET voltage limitation and the substitution of traditional electromagnetic circuit breakers. Experimental validation of the proposed circuits was carried out using Semisouth and SiCED power semiconductors, currently these companies do not exist anymore. Further, in [3] it is suggested the use of paralleled power transistors and parallel multimodule approach.

In chronological order, next interesting reference [5] corresponds to a patent filled in may 2010. It describes power distribution system using bidirectional SSPCs based on two anti-series SiC JFET and anti-parallel diodes.

Three more works date from 2011. In [6] the authors detail the design and the experimental validation of an SSPC based on 1200V/20A SiC MOSFET. Unlike JFET, MOSFET a normally-off device and, therefore, circuit topology is notably different and more similar to what is commonly found with Si devices. Again, main target is aircraft power distribution at $270 \mathrm{Vdc}$. The same group presents in [7] the design and the experimental validation of a Solid State Circuit Breaker (SSCB) capable to operate at high current and high temperature. Finally, in [8] is described a bidirectional $600 \mathrm{~V} / 60 \mathrm{~A}$ SSCB using two SiC normally-on JFET with a common source and single driving circuit for both devices. 
In parallel, from 2010 and 2014 a slightly different SSCB approach is developed using SiC Static Induction Transistors (SIT), which have similar structure to normally-on JFET but smaller channel length, offering less conduction resistance and higher blocking voltage capabilities [9]. $400 \mathrm{Vdc}$ power distribution for data centres was the main application.

During 2015 two related works were also published. In $[10,11]$ is presented a review of the state of art of SSCB using WBG, as well as a complete design using a normally-on SiC JFET, UJN1205K from USCi. SSCB is also validated at $400 \mathrm{~V}$ and $180 \mathrm{~A}$ and the work discusses the benefits of having normally-on devices.

In spite of several application areas are described in those works, none of them is dedicated exclusively to space power electronics. Space high voltage systems, in the range of few $\mathrm{kV}$, are obvious potential candidates to make use of this technology, but also typical space power distribution systems, which are often limited to $100 \mathrm{Vdc}$ in high power satellites and are dominated by Si power MOSFETs could be benefited due to high temperature operation.

To conclude this section and as an anecdote it is worth to mention that Si JFET where proposed as high voltage solid state circuits in the early seventies [12].

\section{BACKGROUND AND INITIAL RESULTS}

Before to initiate the design of a solid state power switch as a basic building block of a SSPC, some considerations and previous experimental results will be described. Those results, which came from other research activities, mainly focus on DC and transient characterization of $\mathrm{SiC}$ power devices.

\subsection{SiC JFET: Infineon IJW120R100T1}

The IJW120R100T1 is a commercially available normally-on SiC JFET from Infineon. It is $1200 \mathrm{~V}$ device with an specified maximum continuous drain source current of $10 \mathrm{~A} \quad\left(\mathrm{~V}_{\mathrm{GS}}=0 \mathrm{~V}, \mathrm{~T}_{\mathrm{C}}=150^{\circ} \mathrm{C}\right.$, $\left.\mathrm{R}_{\mathrm{thJC}}=\mathrm{R}_{\mathrm{thJC}, \max }\right)$.

Normally-on vs. normally-off power devices as solidstate power controllers is an interesting question that should be addressed. At first sight, the traditional approach using normally-off devices seems to be the preferred option; however, recent studies [11,13] also propose the use of normally-on devices.

Anyway, normally-off behaviour can be achieved by using the cascode configuration with a low voltage MOSFET, please refer to figure 1. At initial conditions, the low voltage MOSFET is in off-state and sets the source of the JFET to positive potential relative to its gate, hence JFET remains in off-state. When low voltage MOSFET turns on, gate to source voltage of the JFET goes to zero, keeping it in on-state.

One major drawback for this option is the absence of direct control of the JFET, so different approaches using negative driving signal and always on-state MOSFET are suggested [14].

Another interesting point for cascode configurations is the possibility to create high voltage devices with lower voltage, but faster and lower on-resistence normally-on $\mathrm{SiC}$ JFETs, please refer to figure 1. This structure, known as super cascode, has been recently proposed [15] and it could be of interest in very high voltage applications or to standardize a complete family with different voltages by using the same basic building block.

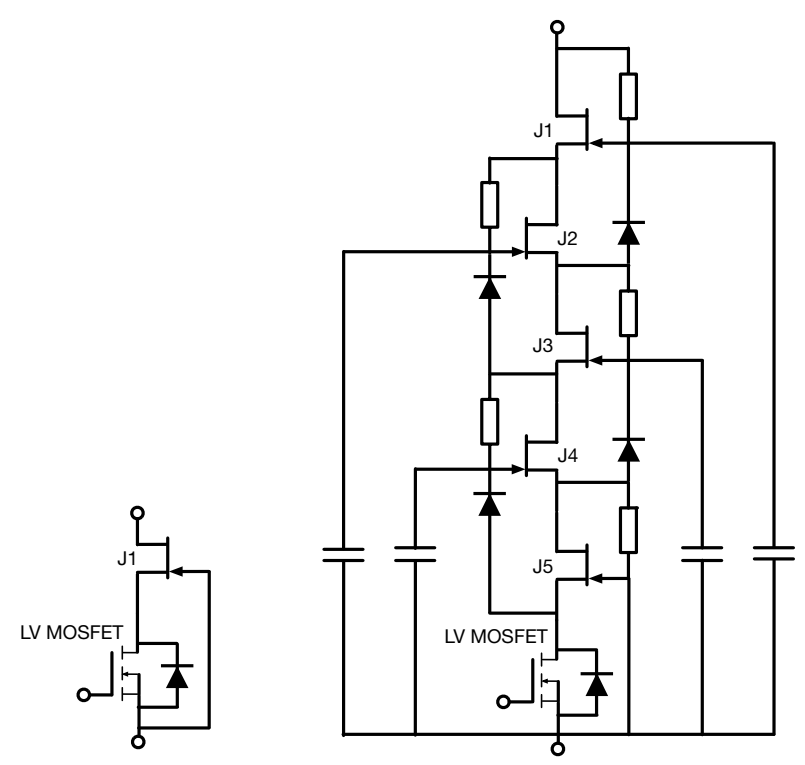

Figure 1. Left side: cascode configuration, right side: super cascode configuration

Next oscilloscope screenshots show the transient response of the IJW120R100T1 working at $25^{\circ} \mathrm{C}$ and $175^{\circ} \mathrm{C}$. Being a protection device, both DC and transient characteristics are extremely important. On-resistance temperature dependence will determine device losses during nominal operation and dynamic characterization including temperature effects is of great importance for driver design and determining turn-off times. On top of this, thermal stress is high in case of operation.

Figure 2 shows switching-on-and-off test with two initial current conditions. First measurement turns on at $0 \mathrm{~A}$ and turns off at 19A. Second measurement turns on at $19 \mathrm{~A}$ and turns off at $28 \mathrm{~A}$. These measurements are performed at $25^{\circ} \mathrm{C}$. 


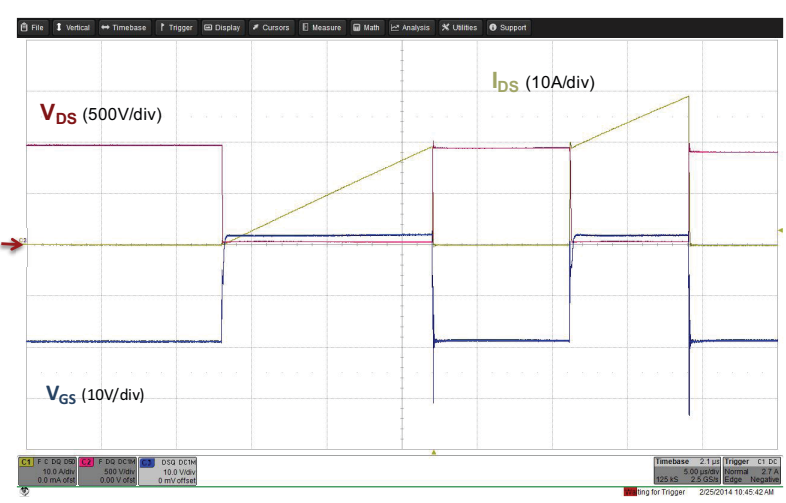

Figure 2. IJW120R100T1 switching characterization. Operating conditions: $V d s=0.8 \cdot V d s(\max ) ; \quad T=25^{\circ} \mathrm{C}$, $V g s=-19 \mathrm{~V} . .2 \mathrm{~V} ; \operatorname{Rg}(\mathrm{on})=20 \mathrm{ohm} ; \operatorname{Rg}(\mathrm{off})=2.4 \mathrm{ohm}$.

The detail of the hard-switching transition at 19A are shown in figure 3 for turn-off and figure 4 for turn-on.

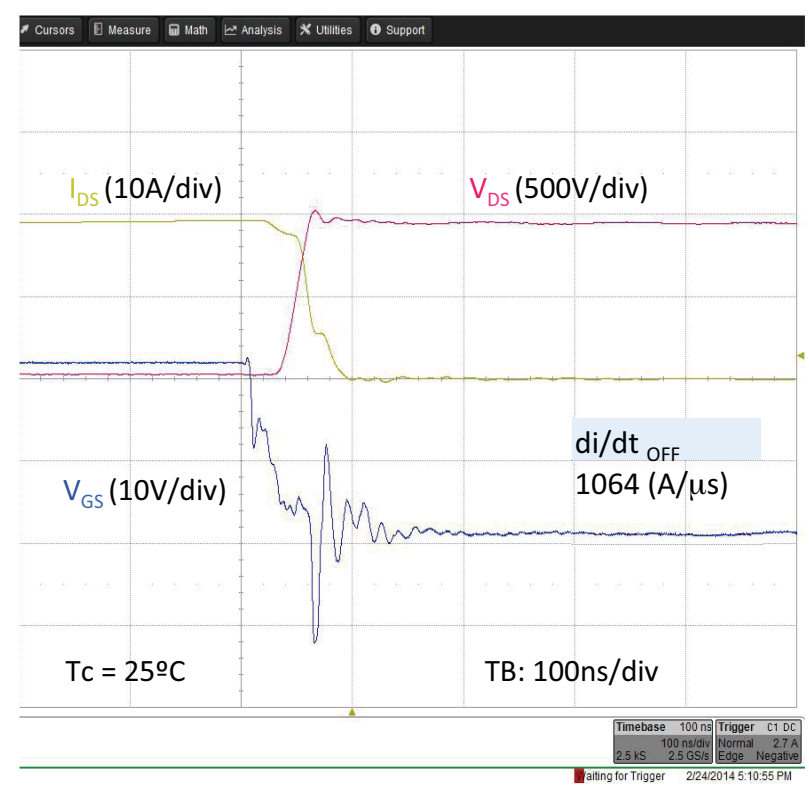

Figure 3. IJW120R100T1 turn-off detail. Operating conditions:

$V d s=0.8 \cdot V d s(\max ) ; \quad I d=0,75 \cdot I d(\max )=19.5 \mathrm{~A}, \quad T=25^{\circ} \mathrm{C}$, $V g s=-19 \mathrm{~V} . .2 \mathrm{~V} ; \operatorname{Rg}(\mathrm{on})=20 \mathrm{ohm} ; \operatorname{Rg}(\mathrm{off})=2.4 \mathrm{ohm}$.

Switching behaviour at $25^{\circ} \mathrm{C}$ and $175^{\circ} \mathrm{C}$ is shown in figures 5 and 6 . One may note that turn-on performance is very similar, dissipated energy in turn-off is at $175^{\circ} \mathrm{C}$ lesser than at $25^{\circ} \mathrm{C}$, also, gate signals remain very similar, indicating that input capacitances do not vary significantly with temperature.

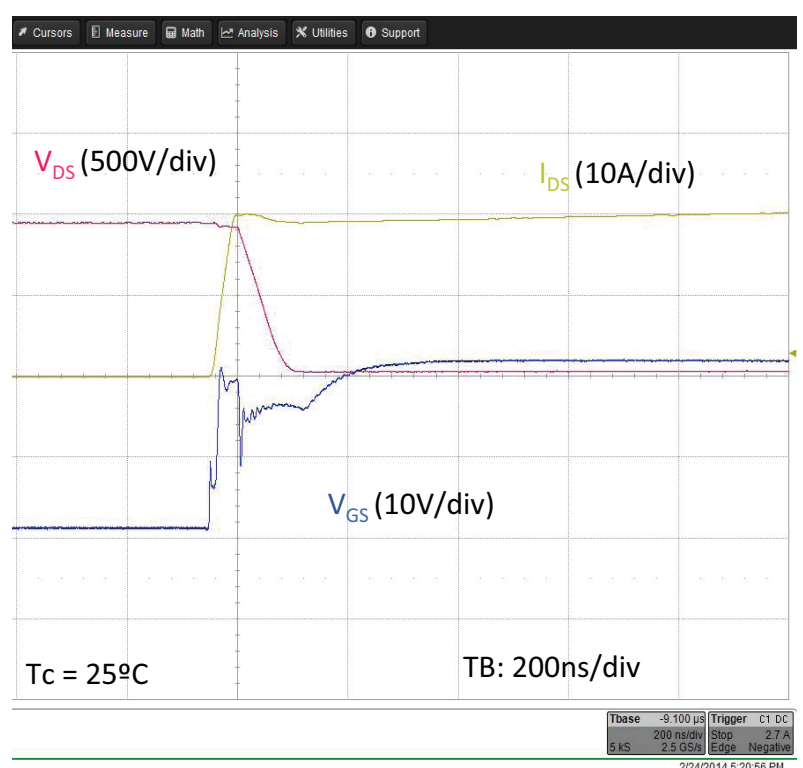

Figure 4. IJW120R100T1 turn-on detail. Operating conditions:

$V d s=0.8 \cdot V d s(\max ) ; \quad I d=0,75 \cdot I d(\max )=19.5 \mathrm{~A}, \quad T=25^{\circ} \mathrm{C}$, $V g s=-19 \mathrm{~V} .2 \mathrm{~V} ; \operatorname{Rg}(\mathrm{on})=20 \mathrm{ohm} ; \operatorname{Rg}(\mathrm{off})=2.4 \mathrm{ohm}$.

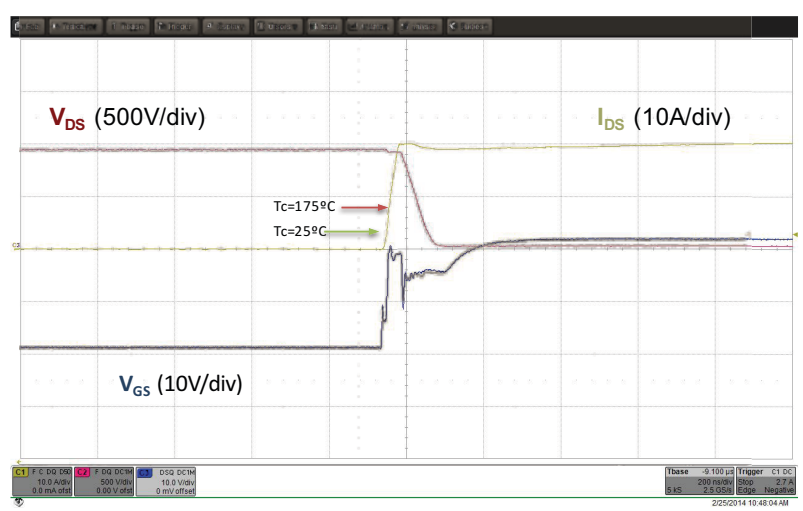

Figure 5. IJW120R100T1 turn-on detail at $25^{\circ} \mathrm{C}$ and $175^{\circ} \mathrm{C}$. Operating conditions:

$V d s=0.8 \cdot V d s(\max ) ; \quad I d=0,75 \cdot I d(\max )=19.5 \mathrm{~A}, \quad V g s=-$ $19 \mathrm{~V} . .2 \mathrm{~V} ; \operatorname{Rg}(\mathrm{on})=20 \mathrm{ohm} ; \operatorname{Rg}(\mathrm{off})=2.4 \mathrm{ohm}$.

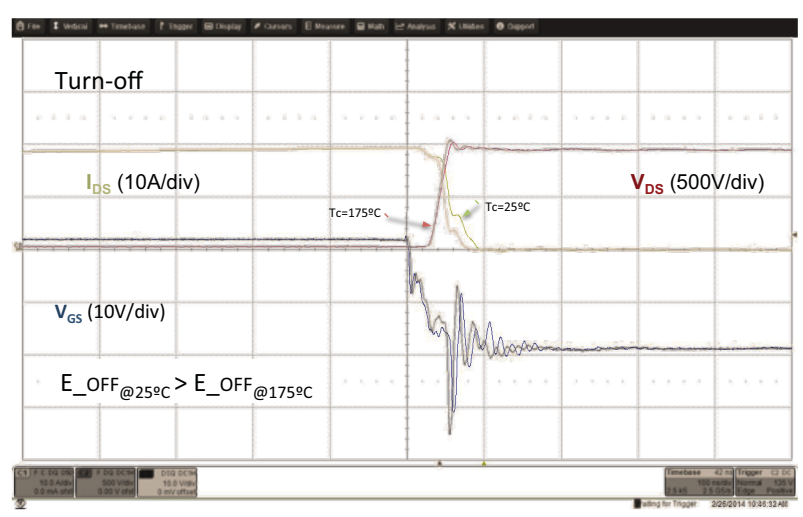

Figure 6. IJW120R100T1 turn-off detail at $25^{\circ} \mathrm{C}$ and 
$175^{\circ} \mathrm{C}$. Operating conditions:

$V d s=0.8 \cdot V d s($ max $) ; \quad I d=0,75 \cdot I d(\max )=19.5 A, \quad V g s=-$ $19 \mathrm{~V} . .2 \mathrm{~V} ; \operatorname{Rg}(\mathrm{on})=20 \mathrm{ohm} ; \operatorname{Rg}(\mathrm{off})=2.4 \mathrm{ohm}$.

\subsection{SiC JFET: USCi UJC1210K}

The UJC1210K is a commercially available JFET SiC integrated cascode in TO-247 package. An SPICE model is also provided by the manufacturer which allows initial circuit design.

Figure 7 shows the simulation schematic of a double pulse circuit, similar to the experimental results presented in the previous section. Simulation results are also included in figures 8 and 9, showing, respectively, switching off and on details.

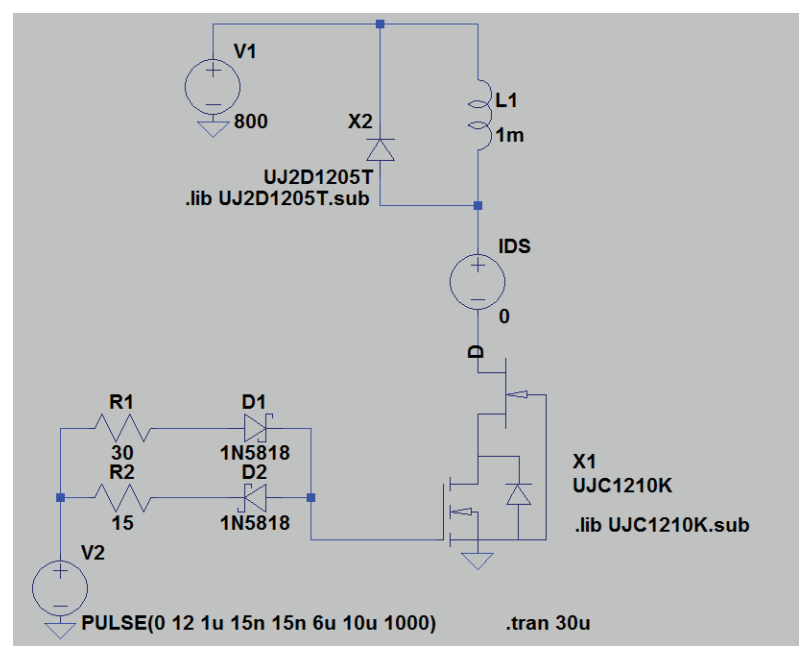

Figure 7. UJC1210K double-pulse LTSpice simulation schematic.

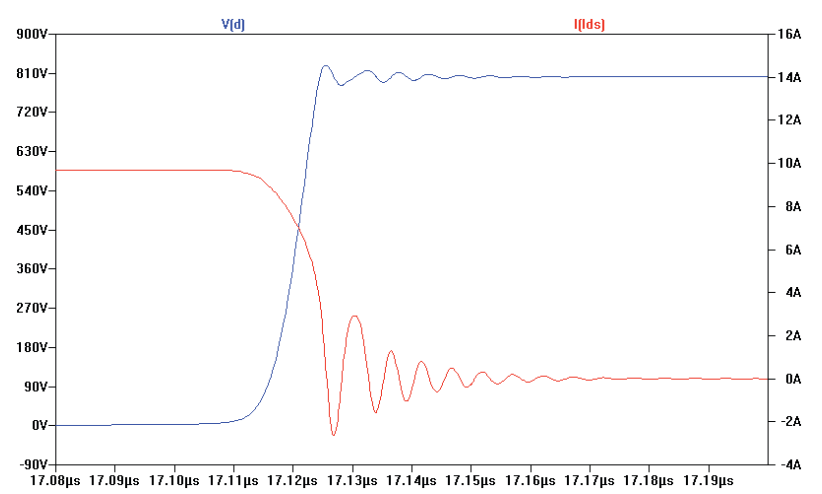

Figure 8. UJC1210K switching off detail. Operating conditions: $V d s=800 \mathrm{~V} ; \mathrm{Id}=10 \mathrm{~A} ; \quad \mathrm{T}=25^{\circ} \mathrm{C} ; \quad \operatorname{Vgs}=0 \mathrm{~V}$.. $12 \mathrm{~V} ;$ Rgon $=30 \mathrm{ohm} ;$ Rgoff $=15 \mathrm{ohm}$.

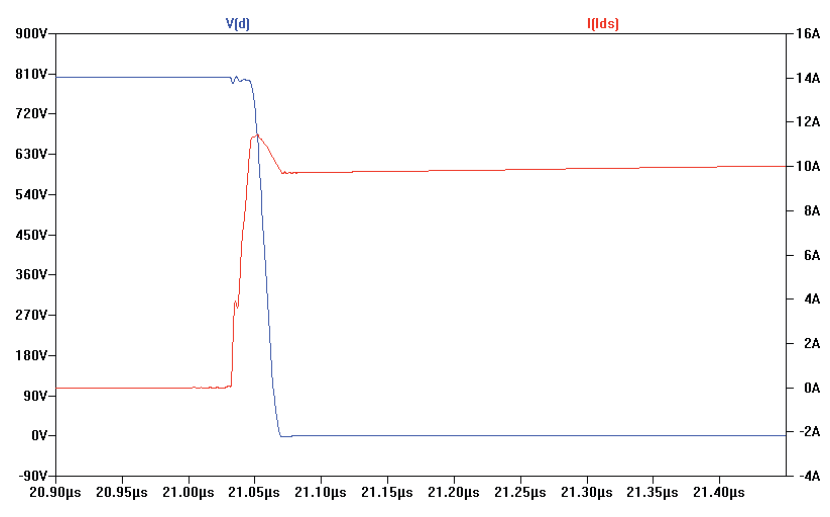

Figure 9. UJC1210K switching on detail. Operating conditions: $V d s=800 \mathrm{~V} ; \quad I d=10 \mathrm{~A} ; \quad T=25^{\circ} \mathrm{C} ; \quad V g s=0 \mathrm{~V}$.. $12 \mathrm{~V} ;$ Rgon $=30 \mathrm{ohm} ;$ Rgoff $=15 \mathrm{ohm}$.

\subsection{MR current sensors}

MR current sensors have been used extensively in industrial, scientific and/or biomedical applications. These sensors are based on a Wheatstone topology resistive bridge that properly biased will bring high voltage sensitivity and linearity (Figure 10). Based on their sensing principle (Biot-Savart law) MR current sensors provide inherent galvanic isolation and nodissipative self heating features [16]. Ultimate MR sensors based on the tunnel MR effect (TMR) provide low offset and hysteresis values with high input impedance and low power supply consumption. Additionally, they offer interesting dynamic response. Figure 11 shows the 0 to +7.5 A step response of a TMR based current sensor compared with a comercial Hall current probe. In the frequency domain, different MR current sensor technologies were studied and modelled [16, 17]. Stability against radiation is a key factor to consider when designing electronic system for spacecraft applications. In this topic various results were obtained on TMR current sensors showing their feasibility to be used in on-board electronic converters, [18]. All the above mentioned features are now being analyzed to be applied in a future SiC-MR based SSPC development.

\section{CONCLUSIONS}

This paper presents the planned activities and some previous results which form the background for a new research project in $\mathrm{SiC}$ based solid state power controllers and the use of magnetoresistive current sensors in space applications. These activities are financially supported by a Spanish national research project which lasts from 2016 to 2018 . First designs and electrical simulations are planned to be carried out during 2016. The field of application is oriented to high voltage systems. 


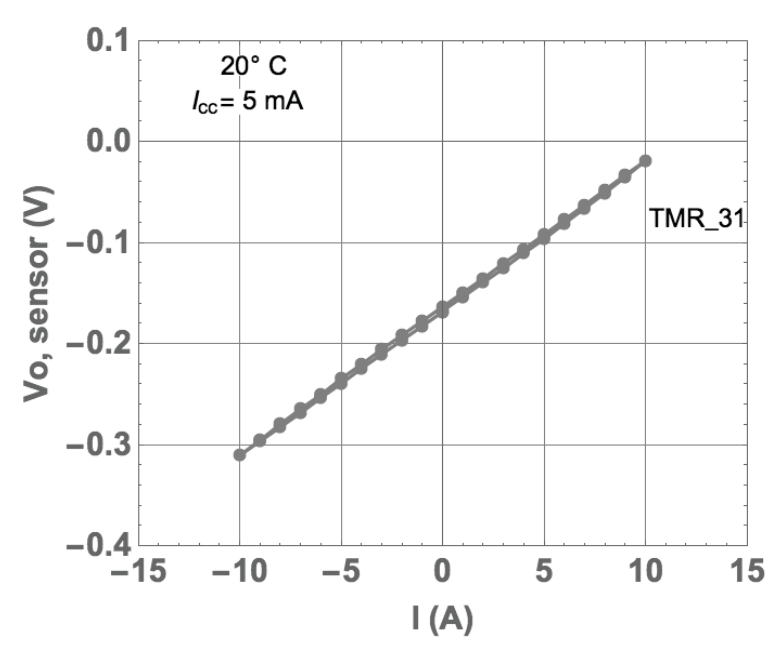

Figure 10. Output voltage of a TMR current sensor under an input current sweep from $-10 \mathrm{~A}$ to $+10 \mathrm{~A}$.

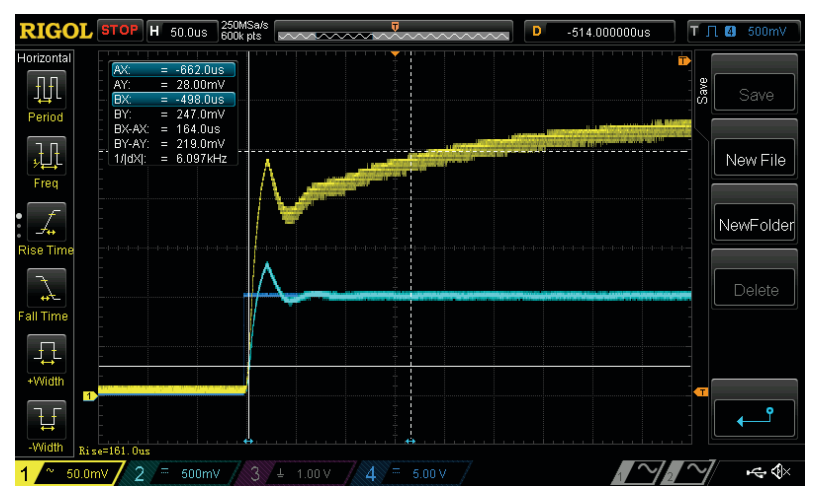

Figure 11. Output voltage of a TMR current sensor under an 7.5A input current step. CH1: TMR output voltage, CH2: Agilent TCP202 Hall current probe output response, CH4: Step control voltage.

\section{ACKNOWLEDGMENTS}

The authors would like to thank the Spanish Ministry of Economy and Competitiveness which has supported these research activities under projects ESP2015-68117C2-1-R and ESP2015-68117-C2-2-R.

\section{REFERENCES}

1. Bausier, F., Massetti, S. \& Tonicello, F. (2014). Silicon Carbide for space power applications, $10^{\text {th }}$ ESPC, Noordwijkerhout, The Netherlands.

2. Slatter, R. \& Goffin, B. (2014). Magnetoresistive current sensors for high accuracy, high bandwidth current measurement in spacecraft power electronics, $10^{\text {th }}$ ESPC, Noordwijkerhout, The Netherlands.
3. Feng, X. (2007). SiC based Solid State Power Controller, University of Kentucky Doctoral Dissertations. Paper 543.

4. Feng, X. \& Radun, A. V. (2008). SiC based Solid State Power Controller, IEEE APEC.

5. Rozman, G. I. \& Swenson, J. C. (2013). Bus-tie SSPCs for DC power distribution system, US8,344,544 B2.

6. Guo, Y. B., Bhat, K. P., Aravamudhan, A., Hopkins D. C. \& Hazelmeyer, D. R. (2011). High current and thermal transient design of a SiC SSPC for aircraft application, IEEE APEC.

7. Bhat, K. P., Guo, Y. B., Yang, Hazelmeyer, D. R. \& Hopkins D. C. (2012). Results for an AI/AIN composite $350^{\circ} \mathrm{C}$ SiC Solid-State Circuit Breaker module, IEEE APEC.

8. Urcioli, D. P., Veladis, V., Ha, H. C. \& Lubormirsky, V. (2011). Demonstration of a 600$\mathrm{V}, 60-\mathrm{A}$, bidirectional silicon carbide solid-state circuit breaker, IEEE APEC.

9. Sato, Y., Tanaka, Y., Fukui, A., Yamasaki, M., \& Ohasi, H. (2014). SiC-SIT circuit breakers with controllable interruption voltage for $400-\mathrm{V}$ DC distribution systems, IEEE Trans. Power Electron. 29(5), 2597-2605.

10. Shen, Z. J., Sabui, G., Miao, Z. \& Shuai, Z. (2015) Wide Bandgap Solid State Circuit Breakers for DC power systems: device and circuit considerations, IEEE Trans. Electron Devices 62(2), 294-300.

11. Miao, Z., et al (2015) A self-powered ultra-fast DC solid state circuit breaker using a normally-on SiC JFET, IEEE APEC.

12. Mitchell, R. R., Ciccanti, A. D. \& Bartlemay J. M. (1970). High voltage solid state switches for space applications, IEEE PESC.

13. Miao, Z., et al (2015). A self-powered bidirectional DC solid state circuit breaker using two normallyon SiC JFETs, IEEE ECCE.

14. -. (2014). CoolSiC 1200V Power Transistor IJW120R100T1 datasheet.

15. Bendel, J. \& Li, X. (2015). Using "normally on" JFETs in power systems, Bodo's Power Systems.

16. Sánchez, J., Ramírez, D., Amaral, S., Cardoso, S., \& Freitas, P. P. (2012). Electrical ammeter based on spin-valve sensor, Review of Scientific Instruments, 83, 105-113.

17. Ravelo, S. I., Ramírez, D., Sánchez, J., Cardoso, S., Ferreira, R. \& Freitas, P. J. P. (2013). Fractional modelling of the AC large-signal frequency 
response in magnetoresistive current sensors, Sensors, 13(12), 17516-17533.

18. Ravelo, S. I., Ramírez, D., Sánchez, J., Cardoso, S., Ferreira, R. \& Freitas, P. J. P. (2015). Total ionizing dose (TID) evaluation of magnetic tunnel junction (MTJ) current sensors, Sensors and Actuators A: Physical, 225, 119-127. 